\title{
Challenges and Opportunities of Cloud Adoption in Supply Chain Management: A SWOT Analysis Model
}

\author{
Panagiota Karvela ${ }^{1}$, Evangelia Kopanaki ${ }^{2}$, Nikolaos Georgopoulos ${ }^{3}$ \\ ${ }^{1}$ Department of Business Administration, University of Piraeus, Piraeus, Greece \\ ${ }^{2}$ Department of Business Administration, University of Piraeus, Piraeus, Greece \\ ${ }^{3}$ Department of Business Administration,University of Piraeus, Piraeus, Greece \\ ${ }^{1}$ pkarvela@unipi.gr; ${ }^{2}$ evik@unipi.gr; ${ }^{3}$ ngeorgop@unipi.gr
}

\begin{abstract}
The contemporary volatile business environment forces firms to seek for IT solutions that will offer flexibility at the level of their supply chain. The main aim of firms is to improve business processes without increasing costs or sacrificing quality. Although cloud computing may support this kind of flexibility, offering advantages like (pay per use model, scalability and information sharing), it also involves many constraints (performance issues, legislation and government laws, locked in data to one provider). Therefore, stakeholders should choose when and why to move business processes to the cloud. To examine these issues, this paper uses a SWOT (Strength, Weakness, Opportunity, Threat) analysis model in order to review and explain the advantages and constraints of cloud computing in the internal and external environment of a firm. SWOT analysis is a very helpful tool for decision-making regarding IT implementation issues and it can be used to analyze the impact of cloud computing solutions on organizations and their supply chains. Based on an extensive literature review, this paper aims to provide a theoretical base for the analysis and evaluation of the complexity of factors that affect the final decision of a firm, regarding the potential adoption of cloud-based solutions by supply chain members.
\end{abstract}

Keywords: Cloud computing, SWOT analysis, cloud service models, supply chain. 


\section{Introduction}

Rapid globalization and intense market competition have led firms to look for advanced information technology solutions to improve their business processes. Generally, firms seek for stable and innovative IT solutions, which support the effective and efficient management of their internal and external operations. They also often seek for low-cost, customizable and scalable solutions. Current advancements in IT give the opportunity to firms, not only to use high-end technology in order to face market competition, but also to avoid huge investments in hardware or software that may become obsolete, within a couple of years (Tiwari \& Jain, 2013, Heisterberg \& Verma, 2014). A key enabler of this "revolution" seems to be cloud computing, which provides a pay-per-use model on firms' needs, including everything from software applications to hardware (servers, storages, networking).

The changes conducted due to COVID 19 pandemic forced firms to seek for quick and low-cost solutions for flexible interconnection, both internally and externally. Their internal processes had to be largely supported by open communication platforms, such as cloud infrastructures, allowing the fast transition to distance work. Although many processes were supported by cloud-based solutions, this did not happen with the core business activities or the interorganizational processes, which continued to be based on more traditional technologies.

The impact of traditional information systems used in supply chain management (e.g EDI, web-based inter-organizational systems) is examined by many researchers (e.g., Karvela et al. 2014, Kopanaki \& Smithson 2013, Tokman et al. 2013, Moitra \& Ganesh, 2005). Most recent research focuses on new technologies (e.g., cloud-based solutions, blockchain technology) and examines their impact on collaboration and supply chain agility (Kopanaki et al. 2018, Karvela et al. 2015, Swafford et al. 2008, Vickery et al., 2010, Heisterberg \& Verma, 2014). According to the literature, the use of cloud computing can transform traditional activities of firms, such as billing processes, forecasting, ordering and logistics, making them accessible via the Internet at any time and in any place (Lindner et al., 2010). In addition, it can be a key enabler for supply chain collaboration and information sharing, and it can provide scalability and efficiency in transactions (Aljabre 2012, Tokman et. al 2013). Hence, through cloud computing, firms may achieve responsiveness and fast reactions to face globalization (Bhoir \& Principal 2014).

However, companies still do not trust open infrastructures, based on the cloud, for their core business processes or for their collaboration with business partners. Security is a major concern for organizations as they still have doubts over data confidentiality (Lawan et al 2020).

This paper examines previous literature and uses a SWOT model to analyze the challenges and opportunities associated with the adoption of cloud-based applications or infrastructures (Sharma \& Sehrawat 2020) by supply chain members. It aims to provide a theoretical and conceptual scheme through which organizations can 
evaluate the implementation not only of cloud-based solutions, but also of other IT infrastructures (Nwagwu 2020).

\subsection{Introduction to cloud-based technologies}

Cloud computing is a technology that could support and provide ubiquitous access and fast information sharing across a supply chain. Leuker et al. (2011 p.17) refer to cloud computing, as "a large pool of readily accessible virtualized resources, which can be transformed and adjusted to customer needs, in a variable scale, giving the opportunity to an optimum use of the provided resource. Cloud computing is a payper-use model which is being guaranteed by Infrastructure Providers by means of Service Level Agreements". Haag and Cummings (2008) define cloud computing as a technology providing web-based applications based on a pay per use and an ondemand resource pooling model. Therefore, cloud computing is a computing infrastructure enabling resources management and offering supply chain capabilities like accessibility, efficiency and scalability.

\subsection{Cloud Service Models}

Cloud computing is a service-oriented architecture (Gold et al., 2004; El-Gayar \& Deokar, 2013; Erol et al., 2014) divided in 3 basic service models (Leukel et al., 2011; Heisterberg \& Verma, 2014) that provide different advantages based on their use. These service models are:

- Software as a Service (SaaS): It is a service that enables customers to use providers' software applications. Customers cannot change, update or control the software that they are using. The advantage of this service, versus traditional software, is the enabled mobility and accessibility, from any place at any time. It is based on a pay per use model that provides customers the capability to use the provider's applications without owning the hardware or software of this application. For example, SupplyOn has developed AirSupply, which is being used by Airbus. It is a cloud-based software in which suppliers and customers of Airbus need to login in order to check the status of their order. Additional examples of SaaS are salesforce.com, Airsupply and Oracle SCM (cloud suite).

- $\quad$ Platform as a Service (PaaS): It is used for the development and deployment of applications. The main difference from SaaS is that PaaS focuses on developers and not on end users. PaaS combines advantages of SaaS giving the possibility to personalize the developed apps based on users' needs. It is based on a pay per use model, which enhances developers' productivity and cost effectiveness. For example, sales information can be combined (revenue per customer, customer preferences, revenue per suppliers) in order to create custom applications with data that will be used to improve strategic decisionmaking. Examples of PaaS are Google App Engine and Windows Azure Cloud Services. 
- Infrastructure as a Service (IaaS): is a service model for managing and monitoring remote infrastructure (servers, storages, switches). Instead of purchasing heavy hardware equipment, IaaS offers the ability to use hardware resources based on changing user's needs with a pay per use model. For example, IaaS solutions may realize and handle periods of demand change (e.g., during Christmas, where demand is greatly increased and more computing power is needed in order to fulfill SC needs). Leading IaaS providers include Amazon Web Services (AWS), Rackspace Open Cloud, and IBM SmartCloud Enterprise.

In addition to the service models analyzed, cloud computing offers 3 basic deployment models that could be combined in order to meet the IT needs of the firm. These deployment models are:

- $\quad$ Private cloud delivers services and is dedicated to a single organization. It is addressed to firms that need autonomy and gives direct control to people/users that are behind the firewall.

- Public cloud gives similar options with private cloud, but, unlike private, it delivers cloud computing services to multiple organizations. It can be used, for example, by start-up businesses that cannot invest in $\mathrm{HW}$ infrastructure. With cloud-based services, they can use from day one resources to quickly develop their business plans.

- Hybrid cloud combines the advantages of public and private cloud computing. It gives the opportunity to firms with existing infrastructure to expand business processes without investing more in hardware.

As the demand of internal users (stakeholders, employees) and external (customers, suppliers) is continually changing, the "computing power" should follow this tempo. Cloud computing offers scalability and computing power could be added or subtracted on an hourly pay per use model (Heisterberg \& Verma, 2014; Leukel et al., 2011).

Table 1: Traditional on premises (HW/SW) in cloud service models

\begin{tabular}{|l|c|c|c|}
\hline \multicolumn{1}{|c|}{ Traditional On Premises } & \multicolumn{3}{c|}{ Service Models } \\
\hline Hardware & IaaS & PaaS & SaaS \\
\hline Servers & $\mathrm{x}$ & & \\
\hline Storage & $\mathrm{x}$ & & \\
\hline Networking & $\mathrm{x}$ & & \\
\hline Software & & & \\
\hline Billing/Invoicing & $\mathrm{x}$ & $\mathrm{x}$ & $\mathrm{x}$ \\
\hline CRM & $\mathrm{x}$ & $\mathrm{x}$ & $\mathrm{x}$ \\
\hline Forecasting & $\mathrm{x}$ & $\mathrm{x}$ & $\mathrm{x}$ \\
\hline Logistics & $\mathrm{x}$ & $\mathrm{x}$ & $\mathrm{x}$ \\
\hline
\end{tabular}




\begin{tabular}{|l|c|c|c|}
\hline Ordering & $x$ & $x$ & $x$ \\
\hline$O / S$ & & $x$ & $x$ \\
\hline
\end{tabular}

\section{Adoption of cloud-based solutions}

\subsection{Traditional Supply chain VS Digital Supply chain}

Traditional supply chain networks were characterized by higher levels of stability operating in a more balanced and secure market (Martin 2016). Product and business cycles could be more easily predicted, while supply chain professionals were focusing on supply chain strategies and cost reduction (Holweg et al., 2005). This was the era when factories were located far from core selling points, but near to low cost labor and cheap raw materials (Naylor et al., 1999). Lean principles were added in supply chain strategies and inventory levels were reduced (Katayama \& Bennett, 1999, Sakaguchi et al., 2004). Changes of existing hardware or software applications were not so frequent or necessary for the survival of firms, as the market was more secure and more stable.

In the contemporary environment, firms face intense competition, market volatility and rapid technological advancements. Nowadays many of our personal activities and data are not only digitized, but also shared (more and more often we are using digital services, such as e-banking, and cloud computing applications, such as drop box, in our everyday life). This intense digitization has also affected supply chain management.

According to Chen et al. (2013) and DeGroote \& Marx (2013), a company should seek for a more updated and mobile supply chain network, in order to achieve sustainable competitive advantage. New and mobile technologies have the potential to transform businesses by making them faster and more ready to absorb the volatility of the market. In the contemporary business environment, organizations should recreate their supply chain into a digital supply chain network, enabling interconnection and trading at the physical dimension (suppliers, products, services, raw materials, distributors, retailers), as well as supporting exchange and sharing of external and internal information, (Aljabre 2012, Heisterberg \& Verma, 2014, Huemer et al. 2008).

In this digital era, cloud computing could further improve supply chain management by enabling adaptability, mobility and cost-efficiency. According to Tiwari \& Jain (2013) and Lindner et al., 2010, it could transform a supply chain into a smart network:

- by improving and leading to responsiveness in an unstable and volatile market environment,

- $\quad$ by providing $24 / 7$ access for all stakeholders,

- by managing the flow of goods from raw materials till distribution to end customers with digital tools and ubiquitous access and 
- $\quad$ by enabling market information to travel fast through digital tools.

\subsubsection{The advantages of the cloud}

Nowadays, a common problem that businesses have to overcome is that information and knowledge of operation (how to?) is held not only locally but most of the times in the departments that are responsible for the specific operation. This weakens the effort of an effective collaboration between different departments or members of a supply chain, increases the possibility of mistakes and decreases the time of response (Baku 2020, Wu et al., 2013). However, a digitized supply chain network can help stakeholders to capture an overall image of their supply chain. Supply chain managers could optimize the entire organization by enhancing collaboration and innovation. Moreover, greater advantages, cost and performance improvements could be achieved by enabling cloud-computing technologies to support supply chain network operations (Chen, 2011, Goyal 2010, Leukel et al., 2011).

Analyzing the impact of cloud computing on supply chain management, we can identify the following capabilities.

1. Flexibility- Scalability

With cloud computing technologies, firms can adjust their computing power depending on their needs (Sharma \& Sehrawat., 2020, Karvela et al., 2015, Heisterberg \& Verma, 2014). Therefore, cloud-based services are ideal for businesses with growing or uncertain requirements. For instance, if there is an increased need for new users (new employees), their needs (in hw and sw) could be fulfilled quickly through pay per use models. With cloud computing it's easy to scale up or scale down the infrastructure and computing capacity needed. As a result, it is easier to add new partners in the supply chain, depending on the demand, and later release them without increasing capital costs.

2. Minimizing Capital-expenditure

It becomes more and more important for CIOs and CFOs to control capex. Cloud computing eliminates the high cost of hardware providing a pay per use model. Based on monthly or even daily needs, a company's computing power can be easily increased or decreased. As a result, periods with insufficient or useless computing power (e.g during the summer) are minimized (Aljabre 2012, Heisterberg \& Verma, 2014).

\section{Cost savings}

Cloud computing technologies not only reduce hardware costs but also the need for in premises IT technicians that are responsible for maintaining systems and data. As payroll is one of the biggest sources of expenditures, it is more cost effective to outsource data storages and software upgrades. According to an IBM survey published in Economist, 31\% said that they like "pay per use" cost model. This is the most obvious reason companies are attracted to (Aljabre 2012, Mazzucca \& Anderson 2015). 


\section{Geographic Distribution/ Increased collaboration}

Cloud computing enables integration and creates a network of collaboration between the firms' departments. It facilitates access of different departments to company's or supply chain's data, enabling and supporting effective collaboration and decision-making. Stakeholders can access edit and share work documents from anywhere at any time. Cloud-based and file sharing applications help them make updates in real time and gives them visibility of collaboration (Karvela et al., 2015, Butner 2010).

\section{Work from anywhere}

It is becoming more and more necessary and efficient from employees to work from home or to access work documents outside the work environment, especially in the era of COVID-19 pandemic (Jasmine 2019, Alashhab et al 2020). Cloud computing may facilitate distance work enabling file sharing and access of company's data via the Internet. Without messing with productivity, the work environment can be more easily brought to home (Tiwari \& Jain, 2013).

6. Information Sharing

Information sharing is facilitated not only between departments of the same company, but also between stakeholders and business partners. As data and information are shared over the network in real time, business processes, such as replenishment and inventory management, can be more precise and efficient. Moreover, as the knowledge about the internal and external environment is available in real time (Fiala 2005, Ngai et al., 2011, Lindner et al. 2010), stakeholders can take more effective business strategy decisions.

\section{Disaster recovery}

Small businesses are more likely to need cloud based recovery and backup systems, that will save them time and money, than big organizations that already have in their premises large systems of storages. A major concern of all businesses today is the what-if recovery and that is why they invest a huge amount of money in on premises hw. However, for smaller firms it is faster and cheaper to look for solutions in the cloud (Wu et al., 2013, Blome et al. 2014).

\section{Compatibility}

Compatibility issues differ from user to user; a company can use existing hw and upgrade it with cloud services or upgrade the existing hardware in order to be compatible with cloud services. Maintenance and upgrades can be done remotely and without the end user noticing it. According to an IBM survey, published by the Economist, - $20 \%$ of respondents refer to this as a benefit with huge potential.

9. Security

Till now, stakeholders and employees were afraid of losing their personal laptops not only for the value, but also for the business documents, files and data stored. Cloud computing provides a level of security, by enabling easy backup and storage of data and work files in the cloud. It also gives users the ability to wipe clean 
remotely their laptop if this gets into the wrong hands.

To sum up, cloud is a trend; it is the next big thing that cannot be ignored. Trends in business tend to change often and quickly, but one trend that can't be ignored is the move towards the cloud. In other words, more and more businesses are adopting cloud-based storage and software solutions. In fact, according to an IDC (International Data Corporation) press release, in the second quarter of 2016 global market for cloud IT infrastructure developed by $14.5 \%$ reaching revenues up to $7.7 \$$ billion. This market includes products such as servers, memories and Ethernet switches used for cloud IT infrastructure. In addition, the total expenditure for cloud infrastructures in EMEA (Europe, Middle East, Africa) region are approximately $9.45 €$ billion reflecting to $36.5 \%$ of total IT infrastructure that is expected to be spent by 2022 .

According to a survey of Cisco presented in the 6th annual exhibition "Cisco Global Cloud Index" cloud traffic will be increased 3.7 times till 2022 (from 3.9 zettabyte (ZB) annually in 2015 to $14.1 \mathrm{ZB}$ in 2022). The significant increase in data traffic is attributed to service models of cloud because of the scalability advantage that they offer compared to traditional data centers. In short, cloud computing is expanding fast and is used more and more by companies.

\subsection{The challenges of the cloud}

However, cloud computing is also associated with constraints and does not provide solutions for all companies' problems. If a firm decides to use cloud-based solutions, it needs to follow many steps in order to realize the desired advantages and capabilities. At first, a firm should choose very carefully the cloud provider and sign a contract. Will it be one provider or multiple? Companies (e.g. Coca Cola) started to understand that it is better to use more than one cloud providers. For example, a company could choose either Azure and office 365 or a SaaS provider for a specific application that does not require customization. Unfortunately, this is not always an easy decision. Each company is different and has different needs that should be examined, before moving to cloud (Nwagwu 2020, Goyal 2010).

An additional challenge of moving to cloud computing is associated with the needs of companies that are part of their supply chain operations. If a member (supplier, logistic company) of the supply chain doesn't agree to move its operations to the cloud and insists of using traditional methods, costs will be probably duplicated and will arise issues of interdependence and interoperability. This may lead to poor performance and to little or not at all flexibility (Baku 2020, Tokman et al. 2013).

Another barrier, that a firm needs to overcome, is the cloud integration that requires a lot of time and effort. In addition, there is a cost of upgrading the old on premises infrastructure to the cloud, unless cloud providers provide compatibility over old versions of HW or operating systems. It is important for companies to come up with a long-term strategy with a cloud provider that will built-in a flexible base/HW. 
In conclusion, there is not a right or a perfect timing for a company to move its processes to the cloud. This depends on the financial depreciation cycle of the on premises HW, the cloud provider and the compatibility level of the technology. If the firm's moving to the cloud is not carefully planned, in all steps of this procedure, all the advantages, discussed before, may become disadvantages and barriers that will cost time and money to the firm.

\section{Opportunities, Threats, Strengths and Weaknesses of moving to the cloud}

As businesses strive for efficiency and effectiveness, they use different decisionmaking tools that help them to analyze the external and internal environment, in order to develop an effective strategy. SWOT analysis is one of the most commonly used tools for improved decision-making and strategic planning. In SWOT analysis strengths and weaknesses are referring to the internal environment of a company, while opportunities and threats to the external. Therefore, SWOT analysis examines the external environment of a firm (threats and opportunities) and links it with its internal processes (strengths, weaknesses), enabling a firm to form and follow a "good" strategy plan, depending on various internal and external factors. Sevkli et al. (2012), argue that the value of SWOT analysis gives firms the opportunity not only to highlight the external and internal factors that affect their business success, but also to determine the important factors needed to develop a long term strategy and achieve competitive advantage (Gao and Peng 2011, Mahesh et al., 2011). There are various subcategories of SWOT analysis that can be used depending on firms' needs (SO strategies, WT, ST). For example, SO strategies (Strength - opportunities) aim to combine strengths with external Opportunities in order to improve business processes, whereas WT strategies aim to develop a defensive stance reducing internal Weaknesses while avoiding external threats.

SWOT analysis is also a very helpful tool for decision-making regarding IT implementation issues (Amin et al., 2011, Bas 2013, Chen 2011), it can be used to analyze the impact of cloud computing solutions on organizations and their supply chains. Based on the literature (Heisterberg \& Verma 2014, Tiwari \& Jain., 2013, Cegielski et al. 2012, Lindner et al. 2010) this section uses a SWOT (Strengths, Weaknesses, Opportunities and Threats) model to analyze the adoption of cloudcomputing technologies by companies and/or supply chains.

The most commonly mentioned factors influencing the adoption of cloud-based technologies are presented in Table 2.

As shown in the following figure, these factors can be associated either with the internal environment of a firm (strengths, weaknesses) or with the external (opportunities or threats). 
Table 2: Factors influencing cloud adoption

\begin{tabular}{|c|c|}
\hline Adoption factors & References \\
\hline Cost Savings & $\begin{array}{l}\text { Aljabre, 2012, Butner, 2010, Mazzucca \& Anderson, } \\
\text { 2015, Furht \& Escalante, 2010, Goyal, 2010, Heisterberg } \\
\text { \& Verma, 2014, Karvela et. al., 2015, Sharma \& } \\
\text { Sehrawat, 2020 }\end{array}$ \\
\hline $\begin{array}{l}\text { Internal Processes (Logistics, } \\
\text { Forecasting, Ordering, Invoicing, } \\
\text { Billing) }\end{array}$ & $\begin{array}{l}\text { Butner, 2010, Heisterberg \&Verma, 2014, Lindner et al., } \\
\text { 2010, Tiwari \& Jain, 2013, Bhoir \& Principal, } 2014 .\end{array}$ \\
\hline Planning & $\begin{array}{l}\text { Butner, 2010, Lindner et. al., 2010, Tiwari \& Jain, 2013, } \\
\text { Bhoir \& Principal, } 2014 .\end{array}$ \\
\hline Security & $\begin{array}{l}\text { Cegielski et. al., 2012, Mazzucca \& Anderson, 2015, } \\
\text { Furht \& Escalante, 2010, Heisterberg \& Verma, 2014, } \\
\text { Karvela et. al., 2015, Lawan et al 2020, Sharma \& } \\
\text { Sehrawat 2020, Tiwari \& Jain, 2013, Zissis \& Lekkas, } \\
2012\end{array}$ \\
\hline Performance Issues & $\begin{array}{l}\text { Cegielski et. al., 2012, Goyal 2010, Heisterberg \& Alakh, } \\
\text { 2014, Karvela et. Al., 2015, Zissis \& Lekkas, } 2012\end{array}$ \\
\hline Software Developers & $\begin{array}{l}\text { Cegielski et. al., 2012, Furht \& Escalante, 2010, Wu et al., } \\
2013\end{array}$ \\
\hline Compatibility Issues & $\begin{array}{l}\text { Cegielski et. al., 2012, Heisterberg \& Verma, 2014, } \\
\text { Karvela et. al., 2015, Wu et al., 2013, Zissis \& Lekkas, } \\
2012\end{array}$ \\
\hline Integration & $\begin{array}{l}\text { Butner 2010, Goyal, 2010, Heisterberg \& Verma, 2014, } \\
\text { Nolan, 2012, Sharma \& Sehrawat 2020, Wu et al., } 2013\end{array}$ \\
\hline Scalability, Resource on Demand & $\begin{array}{l}\text { Aljabre, 2012, Azevedo et al., 2013, Goyal, 2010, Furht \& } \\
\text { Escalante, 2010, Heisterberg \& Verma, 2014, Karvela et } \\
\text { al., 2015, Leukel et al., 2011, Sharma \& Sehrawat 2020, } \\
\text { Tiwari \& Jain, } 2013\end{array}$ \\
\hline Ubiquitous Access & $\begin{array}{l}\text { Cegielski et. al., 2012, Goyal 2010, Furht \& Escalante, } \\
\text { 2010, Heisterberg \& Verma, 2014, Karvela et. Al., 2015, } \\
\text { Nolan, 2012, Tiwari \& Jain, } 2013\end{array}$ \\
\hline Information Sharing & $\begin{array}{l}\text { Azevedo et al., 2013, Cegielski et al., 2012, Heisterberg } \\
\& \text { Verma, 2014, Lindner et al., 2010, Flynn et al. 2010, } \\
\text { Tiwari \& Jain, } 2013\end{array}$ \\
\hline Collaboration & $\begin{array}{l}\text { Aljabre, 2012, Butner, 2010, Cegielski et. al., 2012, Goyal } \\
\text { 2010, Heisterberg \& Verma, 2014, Karvela et. al., 2015, } \\
\text { Sharma \& Sehrawat } 2020\end{array}$ \\
\hline
\end{tabular}


Legislation/ Government

Mazzucca \& Anderson, 2015, Furht \& Escalante, 2010, Heisterberg \& Verma, 2014, Zissis \& Lekkas 2012

Mazzucca \& Anderson, 2015, Furht \& Escalante, 2010,

Lock-in Data/ Providers

Heisterberg \& Verma, 2014, Jun \& Wei, 2011, Leukel et al., 2011

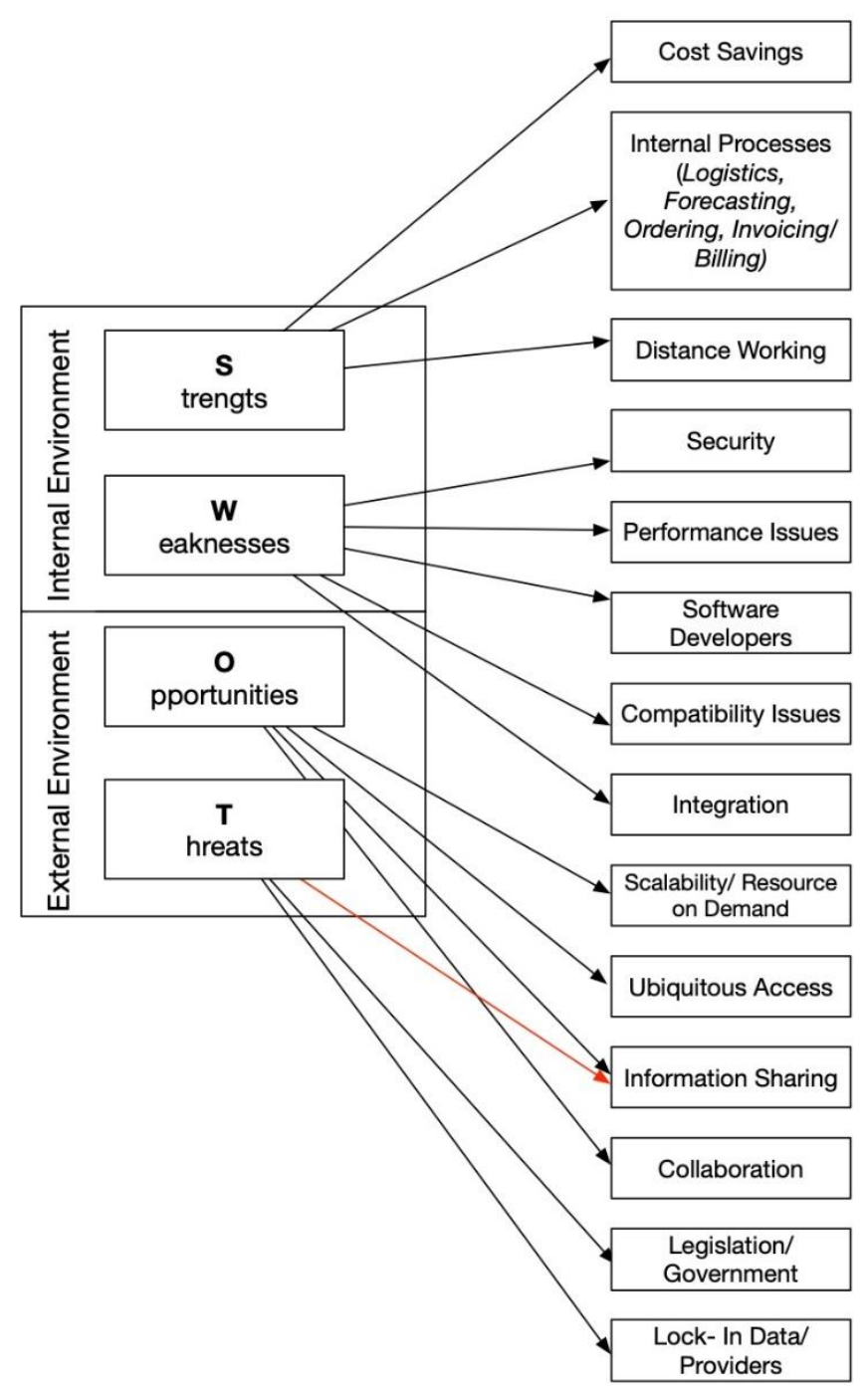

Fig. 1: Theoretical Model-SWOT Analysis

\subsection{Strengths}

One of the most recognizable strengths of cloud computing is the cost minimizing (Heisterberg \& Verma 2014, Tiwari \& Jain, 2013). Cloud computing has the ability 
to use only the hardware required at a specific time. Furthermore, the software is deployed on a central server and is available 24/7 (Sakr et al. 2011). By using cloud computing technology firms can easily control their internal system capabilities and fulfill their needs more accurately using "pay per use" models instead of making huge investments for expensive hardware that within 2 years will be obsolete.

Furthermore, according to Bhoir \& Principal (2014), SaaS enables companies to try modifications on their strategy at a lower cost and without any long commitment. An example of a successful provider of SaaS cloud technology is SalesForce.com. It is ideal for a startup company or a small business that do not want to invest on CRM software. It provides all the tools that a SC needs in order to become more agile and reactive to customer requirements in real time.

In addition, cloud computing facilitates distance working (Alashhab et al 2020) enabling file sharing and access to company's data via the Internet, from anywhere at any time. Without decreasing productivity, the work environment becomes more flexible and can be more easily brought to home (Tiwari \& Jain, 2013).

This flexibility also affects processes, including production scheduling, logistics, forecasting, demand planning and order handling (Tiwari \& Jain, 2013), which can be improved and tracked with cloud computing technologies, with on-time review and access of all stakeholders.

\subsection{Weaknesses}

However, cloud computing technologies have also weak points. In cases where companies deal with sensitive data, like banks, there are security issues regarding not on premises infrastructure (data storages, servers). It is preferred to store this sensitive data in house, where is better protected, than in the cloud, where it can be more easily hacked and leaked (Wu et al, 2013). In addition, there are issues related with integrating data to the cloud, because most of the companies are used to control their data sources. As there is a lack of integration standards in cloud computing, it is impossible for a firm to ensure the quality of its services, when depending on data of its trading partners.

In addition, sometimes important information should be kept out of the cloud because it could lead to important decisions that affect the company's strategy. Hence, it is a difficult task to identify which information should be shared with whom and when, as the cloud could involve all stakeholders. The cloud provides a shared environment, where the security of HW often depends on the way different systems are integrated (especially when some of them are outside of the cloud) (Mishra et al., 2015). Therefore, it becomes more and more complex for companies to check what security policies are supported and required, in order to be more certain and careful with the information that they are exchanging (Zissis \& Lekkas, 2012, Goyal 2010).

Another fact that firms should consider, before moving to the cloud, is the software installation and compatibility with the company's internal processes and needs. This 
requires in house software developers, or outsourced consulting services that provide knowledge for developing applications, based on the particular needs of the firm. However, this may significantly increase cost. When it comes to very specific technical skills (WAN optimization, Citrix presentation, VDI) providers may not offer this kind of specialization, while companies may pay for software without having the knowledge to use it. Furthermore, when it comes to issues of systems' performance, companies are often misleaded, e.g. comparing the storage capacity of cloud providers with the one on premises. However, many providers do not have high performance solid state hard drivers integrated into their systems. As a result, companies often need to pay for an upgraded model that exceeds their budget (Motahari-Nezhad et al., 2009).

\subsection{Opportunities}

In SWOT analysis, opportunities refer to the external environment of a company. Rapid changes of demand forces companies and their supply chains to react fast. With cloud computing, they can achieve scalability. They may build a flexible IT infrastructure, which facilitates the development of business flexibility (Benitez et al.2018). Resources and computing power can be added or removed at any time depending on firms' needs. In addition, users can be added and collaborate as soon as they are logged in with a pay per use model.

Data files, documents and reports can be accessed at any time from any place and the information can be shared across the supply chain (suppliers, distributors, retailers). According to Nazir and Pinsonneault (2012), the cloud minimizes the bullwhip effect, with the on-time information that can travel across the supply chain immediately. Procurement processes (through which products are delivered and stored in the warehouse) may use cloud-based platforms that combine information from multiple sources, providing efficiency and intelligent use of information. For example, SupplyOn platform that is being used by Airbus can handle and combine multiple data and information from suppliers that are located all over the world. The Information can be instantly shared across the supply chain and the demand requests can be handled accordingly (Nolan 2012).

Cloud technologies improve companies' collaboration between all stakeholders (suppliers, distributors, retailers) (Chen 2011). Collaboration between stakeholders becomes easier and updated using information from multiple sources (external and internal) and helping managers to take the right decisions (Karvela et al., 2015, Motahari-Nezhad et al., 2009, Tiwari \& Jain, 2013).

Another example is IBM, that with its cloud-based system proposes a new efficient SCM. With investments that exceed 1 billion dollars, IBM proposes a logistic solution in which all the logistic companies that are operating in Ningbo (one of the biggest ports in China) will be connected. It is estimated that the processing time from this platform has been reduced by $80 \%$ (improved information sharing, better exporting 
services) through Genexus cloud platform.

Cloud technologies provide, to stakeholders, personalized software that generates visibility and access to updated information for all the changes that happen in the external environment of a business (economic, political, credit risks, taxes regulations) that can lead to reduced risk of taking wrong business strategy decisions (Lindner et al. 2010).

Last but not least, cloud computing provides ubiquitous access, real time monitoring of the supply chain which improves efficiency, reduces time and inventory levels, as well as creates long term business relationships between stakeholders (Kembro \& Näslund, 2014).

\subsection{Threats}

Despite the opportunities that the cloud offers, an organization should consider multiple threats that it may have to face.

An environment that is shared and used by multiple members is less secure than a non-shared. The data, documents, work files and sensitive information are uploaded to the cloud. This puts at risk the organization because data files are not located in an actual physical location and are sensitive to any security leakages or improper way of storage, which the organization is not in any position to know or control (Mishra et al., 2015). Another threat that companies face when using cloud computing technologies is that their data are locked in, in a specific provider. They are obliged, based on the contract, to upload their data to a specific provider and if they want, for any reason, to change cloud provider, data need to be transferred from one to another. So, companies do not have any control over their own data when they upload them. To make things worse, even though cloud providers encrypt the data, it is easy to face problems especially if the encryption keys are stored in the same place in the web. Last but not least, uploading data online may be subject to legislation and government laws, which are changing fast enough. Companies are obliged to work under the laws of each government, and this becomes increasingly complex when they collaborate at a global environment, with business partners of several countries.

As shown in the previous sections, SWOT analysis is a very helpful tool for a company to understand the level of its readiness to move to the cloud. If its supply chain is efficient enough or if a fine-tuning using cloud computing technologies is needed. In any case, a decision of moving to the cloud should be taken with caution and after a thorough analysis of pros and cons.

\section{Conclusion}

This paper demonstrated that although cloud computing offers various advantages, it is still associated with risks and constraints. The effective use of cloud computing cannot only decrease cost expenses, but it can also enhance business value by improving internal processes (procurement, planning, billing) and support 
collaboration. Nevertheless, cloud-based technologies can have many drawbacks, as they are still associated with many unresolved issues, including security and compatibility concerns, as well as legislation barriers.

This paper aims to provide a simple conceptual scheme for the evaluation of advantages and disadvantages associated with the adoption of new technologies or IT infrastructures by companies. It then uses this framework to analyze issues related to the adoption of cloud computing. Acknowledging the fact that Strengths may be associated with Weaknesses and that Opportunities may be related to Threats, this paper uses a SWOT model, to analyze the challenges of moving supply chain processes to the cloud. Based on an extensive literature review, the paper shows the potential benefits and risks that a firm or a supply chain could face when using cloudbased solutions.

It is argued that cloud technology provides fast and up to date information sharing, as well as flexibility of various operations or stages of collaboration. However, security and legislation issues are invisible barriers that a firm should overcome in order to use all capabilities offered by the cloud. Therefore, companies should be very careful when deciding which supply chain processes to move to the cloud and which cloud service model to use. They should analyze their needs and take into consideration all weaknesses and threats that have been analyzed in this paper. It is non debatable that the cloud offers numerous advantages and opportunities. However, the complexity of the factors that affect the final decision of a firm, regarding the potential adoption of the cloud, depends on specific characteristics not only of the firm, but also of its supply chain.

\section{References}

Alashhab, Z. R., Anbar, M., Singh, M. M., Leau, Y. B., Al-Sai, Z. A., \& Alhayja'a, S. A. (2020). Impact of Coronavirus Pandemic Crisis on Technologies and Cloud Computing Applications. Journal of Electronic Science and Technology, 100059.

Aljabre, A. (2012). Cloud computing for increased business value. International Journal of Business and Social Science, 3(1), 234-239.

Amin, S. H., Razmi, J., \& Zhang, G. (2011). Supplier selection and order allocation based on fuzzy SWOT analysis and fuzzy linear programming. Expert Systems with Applications, 38(1), 334-342.

Azevedo, S., Prata, P., \& Fazendeiro, P. (2013). Assessment of Supply Chain Agility in a Cloud Computing-based Framework. Scalable Computing: Practice and Experience, 13(4). 
Bas, E. (2013). The integrated framework for analysis of electricity supply chain using an integrated SWOT-fuzzy TOPSIS methodology combined with AHP: The case of Turkey. International Journal of Electrical Power \& Energy Systems, 44(1), 897-907.

Benitez, J., Ray, G., \& Henseler, J. (2018). Impact of information technology infrastructure flexibility on mergers and acquisitions. MIS Quarterly, 42(1).

Bhoir, H., \& Principal, R. P. (2014). Cloud computing for supply chain management. International Journal of Innovations in Engineering Research and Technology, 1(2), 1-9.

Blome, C., Schoenherr, T., \& Eckstein, D. (2014). The impact of knowledge transfer and complexity on supply chain flexibility: A knowledge-based view. International Journal of Production Economics, 147, 307-316.

Butner, K. (2010). The smarter supply chain of the future. Strategy \& Leadership, $38(1), 22-31$.

Cegielski, C. G., Allison Jones-Farmer, L., Wu, Y., \& Hazen, B. T. (2012). Adoption of cloud computing technologies in supply chains. The International Journal of Logistics Management, 23(2), 184-211.

Chen, Y. J. (2011). Structured methodology for supplier selection and evaluation in a supply chain. Information Sciences, 181(9), 1651-1670.

DeGroote, S. E., \& Marx, T. G. (2013). The impact of IT on supply chain agility and firm performance: An empirical investigation. International Journal of Information Management, 33(6), 909-916.

Mazzucca, J. and Anderson, E. (2015). Survey Analysis:Cloud Adoption Across Vertical Industries Exhibits More Similarities Than Differences. Gartner Research. Retrieved from https://www.gartner.com/en/documents/2987617/survey-analysiscloud-adoption-across-vertical-industrie

El-Gayar, O., \& Deokar, A. (2013). A semantic service-oriented architecture for distributed model management systems. Decision Support Systems, 55(1), 374-384.

Erol, O., Sauser, B., \& Boardman, J. T. (2014). Creating Enterprise Flexibility Through Service-Oriented Architecture The Flexible Enterprise (pp. 27-36): Springer.

Fiala, P. (2005). Information sharing in supply chains. Omega, 33(5), 419-423. 
Flynn, B. B., Huo, B., \& Zhao, X. (2010). The impact of supply chain integration on performance: a contingency and configuration approach. Journal of operations management, 28(1), 58-71.

Furht, B., \& Escalante, A. (2010). Handbook of cloud computing (Vol. 3): Springer.

Gao, C.-Y., \& Peng, D.-H. (2011). Consolidating SWOT analysis with nonhomogeneous uncertain preference information. Knowledge-Based Systems, 24(6), 796-808.

Gold, N., Mohan, A., Knight, C., \& Munro, M. (2004). Understanding serviceoriented software. Software, IEEE, 21(2), 71-77.

Goyal, P. (2010, June). Enterprise usability of cloud computing environments: issues and challenges. In 2010 19th IEEE International Workshops on Enabling Technologies: Infrastructures for Collaborative Enterprises (pp. 54-59). IEEE.

Haag, S., \& Cummings, M. (2008). Information Systems Essentials: McGraw Hill Higher Education.

Heisterberg, R., \& Verma, A. (2014). Creating Business Agility: How Convergence of Cloud, Social, Mobile, Video, and Big Data Enables Competitive Advantage: John Wiley \& Sons.

Holweg, M., Disney, S., Holmström, J., \& Småros, J. (2005). Supply chain collaboration:: Making sense of the strategy continuum. European management journal, 23(2), 170-181.

Huemer, C., Liegl, P., Schuster, R., Werthner, H., \& Zapletal, M. (2008, February). Inter-organizational systems: From business values over business processes to deployment. In 2008 2nd IEEE International Conference on Digital Ecosystems and Technologies (pp. 294-299). IEEE.

Jasmine, C. A. (2019). Impacts of Covid-19 on Company and Efforts to Support Organization Adaptable. Dr. David F. Rico, PMP, ACP, CSM, 67-70.

Jun, C., \& Wei, M. Y. (2011). The Research of Supply Chain Information Collaboration Based on Cloud Computing. Procedia Environmental Sciences, 10, 875-880.

Karvela, P., Kopanaki, E., \& Georgopoulos, N. (2014). The impact of Internet-Based Collaboration Platforms on Supply Chain Flexibility. Paper presented at the 
International Conf. of Sustainable Development in Business and Supply Chain Management, University of Brunel, London.

Karvela, P., Kopanaki, E., \& Georgopoulos, N. (2015). Supply Chain Agility Through Cloud Computing Technologies. Paper presented at the Annual International Conference on Business, Marketing and Management, University of Oxford.

Katayama, H., \& Bennett, D. (1999). Agility, adaptability and leanness: a comparison of concepts and a study of practice. International Journal of Production Economics, $60,43-51$.

Kembro, J., \& Näslund, D. (2014). Information sharing in supply chains, myth or reality? A critical analysis of empirical literature. International Journal of Physical Distribution \& Logistics Management, 44(3), 179-200.

Kopanaki, E., Karvela, P., \& Georgopoulos, N. (2018). From traditional interorganisational systems to cloud-based solutions: The impact on supply chain flexibility. Journal of Organizational Computing and Electronic Commerce, 28(4), 334-353.

Kopanaki, E., \& Smithson, S. (2013). The issue of flexibility in inter-organisational collaboration: an appreciative systems thinking perspective. International Journal of Applied Systemic Studies, 5(1-2), 92-113.

Lawan, M. M., Oduoza, C. F., \& Buckley, K. (2020). Proposing a conceptual model for cloud computing adoption in upstream oil \& gas sector. Procedia Manufacturing, $51,953-959$.

Leukel, J., Kirn, S., \& Schlegel, T. (2011). Supply Chain as a Service: A Cloud Perspective on Supply Chain Systems. Systems Journal, IEEE, 5(1), 16-27. doi:10.1109/JSYST.2010.2100197

Lindner, M., Galán, F., Chapman, C., Clayman, S., Henriksson, D., \& Elmroth, E. (2010). The cloud supply chain: A framework for information, monitoring, accounting and billing. Paper presented at the 2nd International ICST Conference on Cloud Computing (CloudComp 2010).

Mahesh, S., Landry, B. J., Sridhar, T., \& Walsh, K. R. (2011). A decision table for the cloud computing decision in small business. Information Resources Management Journal (IRMJ), 24(3), 9-25. 
Mishra, A., Mishra, T., \& Assouma, S. S. (2015). Review on Risks and Risk Management in Cloud Platform. International Journal of Engineering, Technology, Science and Research (IJETSR).

Moitra, D., \& Ganesh, J. (2005). Web services and flexible business processes: towards the adaptive enterprise. Information \& Management, 42(7), 921-933.

Motahari-Nezhad, H. R., Stephenson, B., \& Singhal, S. (2009). Outsourcing business to cloud computing services: Opportunities and challenges. IEEE Internet Computing, 10 .

Nazir, S., \& Pinsonneault, A. (2012). IT and Firm Agility: An Electronic Integration Perspective. Journal of the Association for Information Systems, 13(3).

Ngai, E. W., Chau, D. C., \& Chan, T. (2011). Information technology, operational, and management competencies for supply chain agility: Findings from case studies. The Journal of Strategic Information Systems, 20(3), 232-249.

Nolan, R. L. (2012). Ubiquitous IT: The case of the Boeing 787 and implications for strategic IT research. The Journal of Strategic Information Systems, 21(2), 91-102.

Nwagwu, U. (2020). A SWOT analysis on the use of blockchain in supply chains. Doctoral Dissertation. Wichita State University.

Sakaguchi, T., Nicovich, S. G., \& Dibrell, C. C. (2004). Empirical evaluation of an integrated supply chain model for small and medium sized firms. Information Resources Management Journal (IRMJ), 17(3), 1-19.

Sakr, S., Liu, A., Batista, D. M., \& Alomari, M. (2011). A survey of large scale data management approaches in cloud environments. IEEE Communications Surveys \& Tutorials, 13(3), 311-336.

Sevkli, M., Oztekin, A., Uysal, O., Torlak, G., Turkyilmaz, A., \& Delen, D. (2012). Development of a fuzzy ANP based SWOT analysis for the airline industry in Turkey. Expert Systems with Applications, 39(1), 14-24.

Sharma, M., \& Sehrawat, R. (2020). Quantifying SWOT analysis for cloud adoption using FAHP-DEMATEL approach: evidence from the manufacturing sector. Journal of Enterprise Information Management.

Swafford, P. M., Ghosh, S., \& Murthy, N. (2008). Achieving supply chain agility through IT integration and flexibility. International Journal of Production Economics, $116(2), 288-297$. 
Tiwari, A., \& Jain, M. (2013). Analysis of supply chain management in cloud computing. International Journal of Innovative Technology and Exploring Engineering, 3(5), 152-155.

Tokman, M., Richey Jr, R. G., Morgan, T. R., Marino, L., \& Dickson, P. H. (2013). SME supply chain portfolios: firm satisfaction and organization resources. International Journal of Logistics Management, The, 24(2), 271-300.

Vickery, S., Droge, C., Setia, P., \& Sambamurthy, V. (2010). Supply chain information technologies and organisational initiatives: complementary versus independent effects on agility and firm performance. International Journal of Production Research, 48(23), 7025-7042.

Wu, Y., Cegielski, C. G., Hazen, B. T., \& Hall, D. J. (2013). Cloud computing in support of supply chain information system infrastructure: understanding when to go to the cloud. Journal of Supply Chain Management, 49(3), 25-41.

Zissis, D., \& Lekkas, D. (2012). Addressing cloud computing security issues. Future Generation Computer Systems, 28(3), 583-592. 